\title{
Blefaroplastia em coelhos por meio de cartilagem auricular alógena conservada em solução saturada de $\mathrm{NaCl}$
}

\author{
[Rabbits eyelid repair by means of alogen auricular cartilage preserved in $\mathrm{NaCl}$ saturated solution] \\ L.B. Baungarten ${ }^{1}$, P.M.C. Freitas ${ }^{2}$, D. Eurides $^{3}$, A.E.P. Salgado ${ }^{4}$ \\ L.C. Nunes ${ }^{2}$, M.E. Beletti $i^{3}$ \\ ${ }^{1}$ Aluna de pós-graduação - UFU- Uberlândia, MG \\ ${ }^{2}$ Universidade Federal do Espírito Santo - UFES - Alegre, ES \\ ${ }^{3}$ Faculdade de Medicina Veterinária - UFU - Uberlândia, MG \\ ${ }^{4}$ Aluna de graduação - UNIUBE - Uberaba, MG
}

\begin{abstract}
RESUMO
Avaliou-se a reconstrução da pálpebra inferior de coelhos, com cartilagem auricular alógena, conservada em solução saturada de $\mathrm{NaCl}$ em 12 coelhos, adultos, de ambos os sexos. Os animais receberam acepromazina $(0,5 \mathrm{mg} / \mathrm{kg} / \mathrm{IM})$ e tiletamina e zolazepam $(7,0 \mathrm{mg} / \mathrm{kg} / \mathrm{IM})$, após o que removeu-se um fragmento de $1,0 \times 0,5 \mathrm{~cm}$ das pálpebras inferiores, esquerda e direita. A pálpebra esquerda foi reparada pela técnica de blefaroplastia em $\mathrm{H}(\mathrm{GC})$ e a direita por um retalho de cartilagem auricular associado a blefaroplastia em H (GE). Aos sete dias de pós-operatório (PO), as feridas cirúrgicas dos animais do GC apresentavam retração cutânea. Aos 15 dias de PO, observou-se que as feridas nos coelhos do GE estavam cicatrizadas, mas $30 \%$ das do GC apresentavam deiscência e retração cicatricial. Aos 30 dias de $\mathrm{PO}$, as feridas nos animais do GE e GC apresentavam-se cicatrizadas, mas, 30\% nos do GC não apresentavam as bordas das feridas coaptadas. $\mathrm{O}$ enxerto de cartilagem auricular diminuiu a retração cicatricial, possibilitando reparo anatômico à pálpebra.
\end{abstract}

Palavras-chaves: coelho, cirurgia, cartilagem auricular, enxerto, pálpebras

\begin{abstract}
The rabbit inferior eyelid repair was evaluated using $\mathrm{NaCl}$ satured-stored alogenous auricular cartilage. Twelve adult male and female rabbits had a $1.0 x 0.5 \mathrm{~cm}$ fragment removed from the left and right inferior eyelids after pre-medication with acepromazine $(0.5 \mathrm{mg} / \mathrm{kgIM})$ and tiletamine-zolazepan (7.0mg/kgIM) anesthesia. The " $H$ " plasty technique was used to the left eyelid repair $(C G)$ and the right one was repaired with auricular cartilage associated with the " $H$ " plasty technique $(G G)$. The CG wounds presented cutaneous retraction at day $7^{\text {th }}$ of the post-operative period. The GG wounds were healed on the day $15^{\text {th }}$, while the CG wounds presented $30 \%$ of deiscence and cicatricial retraction. The GG and $C G$ wounds were healed at day $30^{\text {th }}$ of the post-operative period, but $30 \%$ of the CG wounds did not present the edges lined up. It was concluded that the auricular cartilage graft decreases cicatricial retraction and improves anatomical eyelid repair.
\end{abstract}

Keywords: auricular cartilage, surgery, graft, eyelid

Recebido em 9 de fevereiro de 2007

Aceito em 3 de setembro de 2007

Endereço para correspondência (corresponding address)

Av. João Pinheiro, 4670/102 - 38405-310 - Uberlândia, MG

E-mail: leticiabinda@yahoo.com.br 


\section{INTRODUÇÃO}

As pálpebras e o ato de piscar são indispensáveis para a distribuição do líquido lacrimal, a proteção da córnea e a eliminação de corpos estranhos da superfície ocular. Assim, qualquer alteração nas pálpebras pode comprometer tais funções (Moore, 1996). Várias são as causas que podem alterar a anatomia e fisiologia das pálpebras, como feridas por mordeduras, lesões causadas por acidentes diversos e neoplasias.

O tratamento de neoplasias palpebrais em cães e gatos consiste na ressecção de toda a espessura da pálpebra e posterior oclusão primária (Lewin, 2003). Entretanto, segundo Brightman e Helper (1978), esse procedimento pode ser utilizado para reparo de lesões que envolvam até um terço da margem palpebral. Assim, tumores que envolvam a excisão de um terço ou mais da pálpebra requerem o uso de técnicas especiais de restauração (Slatter, 1990).

De acordo com Schmid et al. (2005), a técnica de flaps cutâneos é indicada para a correção de defeitos extensos, tanto de pálpebra superior quanto inferior. Porém, segundo Slatter (1990), essa deve ser utilizada quando há remoção parcial da pálpebra, onde se preserva a conjuntiva palpebral Caso contrário, devem-se utilizar os enxertos para sua reparação.

Pena e Garcia (1999), após enxertarem mucosa oral em uma lesão de três quartos da pálpebra superior de um cão, observaram que houve retorno das funções palpebrais, assim como da sua anatomia. Após utilizarem cartilagem auricular autógena, para reparo de pálpebra no homem, Jackson et al. (1989) verificaram que esse enxerto proporcionou excelente estabilidade ao tecido palpebral. Marks et al. (1989), ao utilizarem o mesmo tipo de enxerto no homem, constataram que a cartilagem, quando enxertada em defeito palpebral, melhora a cicatrização tecidual e diminui seu processo de retração.

As membranas biológicas, pela facilidade de obtenção e conservação e pelo custo reduzido, surgiram nos últimos anos como uma alternativa de material destinado a enxertos (Freitas, 2006; Sampaio et al., 2006). Freitas (2003), após reparar a parede torácica de coelhos com cartilagem auricular de cães, relatou que houve integração do enxerto com ausência de contaminação e fragilidade tecidual.
O tecido cartilaginoso apresenta capacidade para adaptar-se à área receptora, sendo moldado e completamente envolvido pelo tecido do hospedeiro. É utilizado para constituir um arcabouço para o desenvolvimento de tecidos do receptor, podendo permanecer no leito hospedeiro durante tempo indefinido (Gabrielli et al., 1986). Sua fraca antigenicidade deve-se ao fato de ser um tecido avascular (Banks, 1992).

Diversos são os meios de conservação para biomateriais citados na literatura. Um deles, a solução saturada de $\mathrm{NaCl}$, foi utilizada por Brun et al. (2002) e Freitas (2006) para preservação de pericárdio e peritônio de bovino, respectivamente. Os autores relataram que esse meio possui propriedade anti-séptica, além de manter as características estruturais do tecido.

O objetivo deste estudo foi avaliar clinica, macroscopica e microscopicamente a reconstrução de pálpebra inferior de coelhos, com enxerto de cartilagem auricular alógena, conservada em solução saturada de $\mathrm{NaCl}$.

\section{MATERIAL E MÉTODOS}

Foram utilizados 12 coelhos, sem raça definida, adultos, de ambos os sexos. Os animais submetidos a exames clínico e hematológico, foram alojados em gaiolas individuais durante um período mínimo de 30 dias para adaptação ao local, onde receberam alimentação, água à vontade e manejo adequado.

As cartilagens auriculares, coletadas de coelhos adultos, após o abate, em criadouro particular, foram lavadas por várias vezes com solução de cloreto de sódio a $0,9 \%{ }^{1}$ e colocadas em frascos estéreis com solução saturada de $\mathrm{NaCl}$, na proporção de $1,5 \mathrm{~g}$ de sal comercial para $1 \mathrm{ml}$ de água destilada. Permaneceram submersas na porção sedimentada da solução em temperatura ambiente por, no mínimo, 30 dias. O tecido foi retirado do frasco de conservação 30 minutos antes do procedimento cirúrgico, lavado abundantemente em solução de cloreto de sódio a $0,9 \%$ e imerso na mesma solução com enrofloxacina ${ }^{2}$.

${ }^{1}$ Sanobiol - Pouso Alegre, Brasil.

${ }^{2}$ Vallé Produtos Veterinários - Montes Claros, Brasil.

${ }^{3}$ Univet S.A. - São Paulo, Brasil.

${ }^{4}$ União Química Farmacêutica Nacional - Pouso Alegre, Brasil.

${ }^{5}$ União Química Farmacêutica Nacional - Guaçu, Brasil.

${ }^{6}$ Zoletil 50, Virbac - São Paulo, Brasil.

${ }^{7}$ Rioquímica Indústria Farmacêutica - São José do Rio Preto, Brasil. 
Após jejum hídrico e alimentar de quatro horas, os coelhos receberam maleato de acepromazina $0,2 \%{ }^{3}$ $(0,5 \mathrm{mg} / \mathrm{kg} / \mathrm{IM})$. Foi administrado o antibiótico enrofloxacina $(10 \mathrm{mg} / \mathrm{kg})$, o analgésico cloridrato de tramadol $^{4} \quad(1 \mathrm{mg} / \mathrm{kg})$ e o antiinflamatório cetoprofeno ${ }^{5}(2,0 \mathrm{mg} / \mathrm{kg}$, ) todos por via subcutânea, 30 minutos antes do procedimento cirúrgico. A indução e manutenção anestésica foram realizados com tiletamina e zolazepam ${ }^{6} \quad(7,0 \mathrm{mg} / \mathrm{kg} / \mathrm{IM})$. Depois de anestesiados, realizou-se a tricotomia da região palpebral inferior direita e esquerda e antisepsia dos campos operatórios com polivinilpirrolidona-iodo tópico ${ }^{7}$.

Com o animal contido em decúbito lateral direito na mesa operatória, foi removido com bisturi um segmento de espessura total de $1,0 \times 0,5 \mathrm{~cm}$ da margem palpebral inferior esquerda. Após, realizou-se uma incisão e divulsão da pele, com avanço desta sobre o defeito palpebral, sendo denominado de grupo controle (GC). A pele foi fixada por pontos simples separados com fio náilon 5- $0^{8}$. Imediatamente após, procedimento idêntico foi realizado na pálpebra inferior direita, porém, após a incisão de pele, um retalho de $1,0 \times 0,5 \mathrm{~cm}$ de cartilagem auricular, já reidratada, foi fixado à placa tarsal, por pontos simples separados com categute cromado 5- $0^{9}$, sendo esse denominado de grupo com enxertia (GE) (Fig. 1).

No pós-operatório (PO) foram utilizados enrofloxacina por cinco dias, cetoprofeno por três dias, ambos a cada 24 horas e cloridrato de tramadol a cada 12 horas durante três dias, nas mesmas doses utilizadas no pré-operatório. Aplicou-se bandagem aderente e oclusiva hidroativa estéril com gel ${ }^{10}$ e colírio oftálmico de dexametasona $0,1 \%$, sulfato de neomicina $0,35 \%$ e sulfato de polimixina B $6000 \mathrm{UI}^{11}$. Os animais permaneceram com colar elisabetano fabricado com filme de raio $\mathrm{X}$ até a retirada dos pontos, após 10 dias de PO.

Decorridos os períodos pré-determinados de sete, 15 e 30 dias de PO, os coelhos foram sacrificados com sobredose de tiopental sódico ${ }^{12}$ e cloreto de potássio $^{13}$, conforme recomendado pelo código de ética para o uso de animais em pesquisas científicas. Foram coletados fragmentos da

\footnotetext{
${ }^{8}$ Shalon Fios Cirúrgicos - São Luís de Montes Belos, Brasil.

${ }^{9}$ Brasmédica S/A Indústria Farmacêutica - São Paulo, Brasil.

${ }^{10}$ Bristol-Myers Squibb Farmacêutica - São Paulo, Brasil.

${ }^{11}$ Alcon Laboratórios do Brasil - São Paulo, Brasil.

${ }^{12}$ Cristália Produtos Químicos Farmacêuticos - São Paulo, Brasil.

${ }^{13}$ Equiplex Indústria Farmacêutica - Goiânia, Brasil.
}

integração enxerto e tecidos adjacentes, posteriormente fixados em formol a $10 \%$ e submetidos à inclusão em parafina. Os cortes histológicos foram corados pela técnica hematoxilina e eosina e tricrômico de Gômori. As lâminas foram avaliadas em microscópio de luz para verificação da integração tecidual do segmento enxertado. Os achados histológicos foram agrupados quantitativamente utilizando-se escalas de 0 a 3 , com as seguintes qualificações: $0=$ ausência de alterações; $+=$ alterações discretas; $++=$ alterações moderadas e $+++=$ alterações severas.

\section{RESULTADOS E DISCUSSÃO}

Realizou-se a secção de um fragmento de $1,0 \times 0,5 \mathrm{~cm}$ da margem palpebral, o que corresponde, no coelho, a ressecção aproximada de $50 \%$ de sua pálpebra inferior. Esse procedimento foi necessário para a reconstrução palpebral com enxerto, pois segundo Slatter (1990) e Pena e Garcia (1999), em defeitos maiores que um terço da margem palpebral, devem-se utilizar enxertos reconstituitivos.

Decorridos 24 horas do procedimento cirúrgico, observou-se moderada secreção serosa e hiperemia cutânea na ferida, tanto do grupo com a enxertia (GE) quanto no grupo-controle, somente com a blefaroplastia (GC), devido à fase exsudativa da inflamação. Segundo Jones et al. (2000), nesse período do reparo tecidual, pode-se observar hiperemia cutânea pela dilatação dos vasos, aumento da circulação sangüínea e a liberação de mediadores inflamatórios que produzem substâncias como histamina, bradicinina e prostaglandinas, que concorrem para a hiperemia local.

Aos sete dias de PO, as feridas cirúrgicas dos animais dos dois grupos apresentavam discreta hiperemia cutânea e mínima secreção serosa. Isto, provavelmente, deveu-se ao fato de tais feridas se encontrarem na fase proliferativa de cicatrização, tendo um decréscimo no nível dos mediadores inflamatórios, reduzindo, assim, a inflamação (Abla e Ishizuka, 1995). Nos animais do GC notou-se retração cutânea expressiva comparada aos do GE, devido à contração cicatricial que ocorre na fase reparadora de aproximadamente $20 \%$ (Stegman et al., 1982). Na avaliação microscópica, verificou-se presença de cartilagem na ferida dos animais do GE e nos dois grupos, discreto número de células inflamatórias, neovascularização, tecido de granulação imaturo e desorganizado e, ainda, hemorragia. 


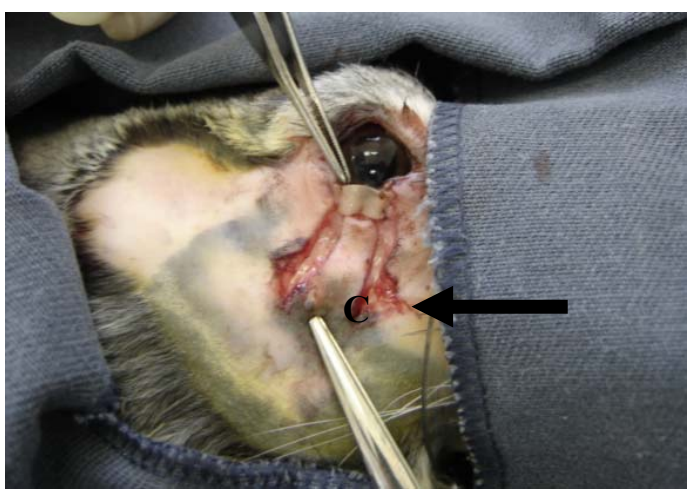

Figura 1. Enxerto de cartilagem auricular alógena em pálpebra de coelho. Observa-se no procedimento cirúrgico um retalho de cartilagem auricular $(\mathrm{C})$ fixo à placa tarsal por pontos simples separados com categute cromado 5-0 (seta).

Aos 15 dias de PO, notou-se nos coelhos GC retração cicatricial e conseqüente deiscência de ferida com secreção serosa, lacrimejamento e fotobobia em 30\% dos animais. Este resultado assemelha-se ao relatado por Marks et al. (1989), que após utilizarem enxerto de cartilagem auricular autógena na pálpebra de homem, comentaram que a utilização de cartilagem em enxertos palpebrais diminui o processo de retração cutânea. $\mathrm{Na}$ avaliação microscópica, verificou-se, nos animais do GE, presença da cartilagem auricular degradada e incorporada ao hospedeiro, com discreta quantidade de células inflamatórias e quantidade moderada de tecido de granulação imaturo e organizado (Fig. 2). Tal fato ocorreu devido ao colágeno da cartilagem que removeu o excesso de exsudado, promoveu a granulação e acelerou a epitelização (Mandelbaum et al., 2003). Na ferida nos do GC foi observado pouco tecido de granulação imaturo e desorganizado, com moderada neovascularização, enquanto nos do GE notou-se discreta quantidade de vasos sangüíneos, resultado do processo de cicatrização que encontrava-se mais avançado comparado ao do GC. Além disso, em $30 \%$ dos animais do GC notou-se intensa vasculite, devido à lesão tecidual originada da deiscência da ferida, que provocou inflamação do vaso, como o descrito por Jones et al. (2000).

Decorridos 30 dias de PO, as feridas cirúrgicas em todos os coelhos apresentavam-se cicatrizadas. Nos animais do GC, onde houve deiscência da ferida aos 10 dias de PO, a pele apresentava-se com uma depressão na margem palpebral devido à retração cicatricial (Fig. 3-A), fato não observado nos do GE (Fig. 3-B).

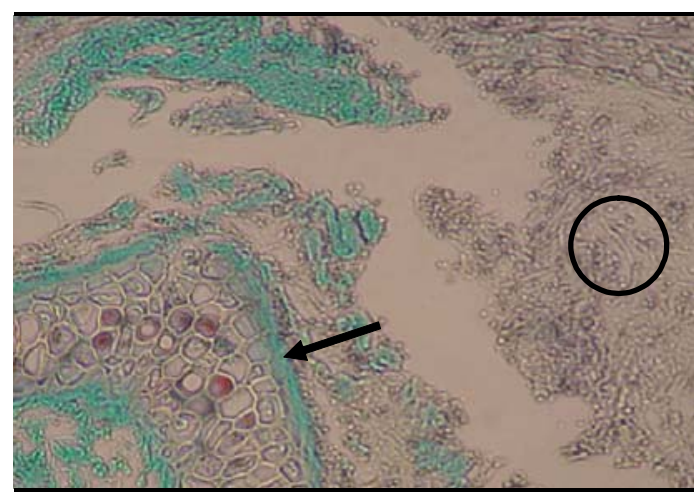

Figura 2. Fotomicrografia da área da pálpebra inferior direita, reparada com cartilagem auricular alógena, associada à blefaroplastia, aos 15 dias de pósoperatório. Observa-se tecido de granulação imaturo e organizado (círculo) próximo à cartilagem auricular (seta). TG - 100x.

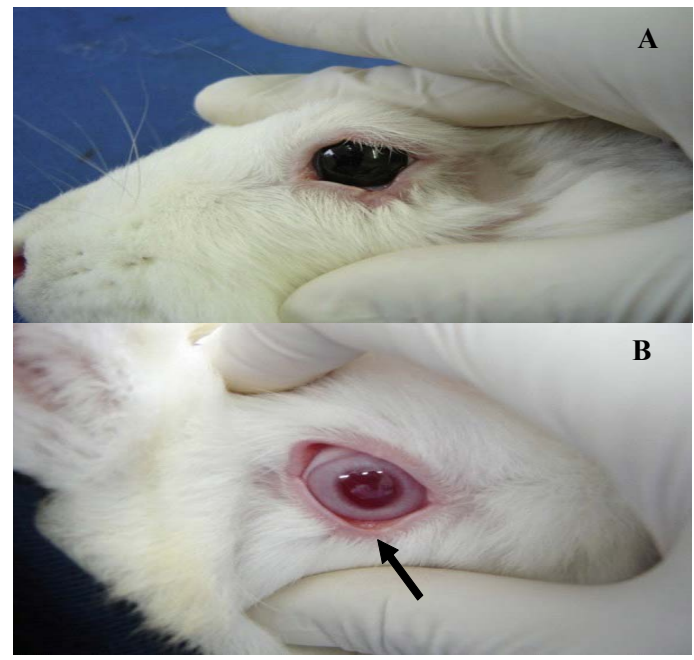

Figura 3. A: Aspecto macroscópico da área da pálpebra inferior esquerda de coelho reparada com a técnica de blefaroplastia, aos 30 dias de pósoperatório. Observa-se um defeito anatômico na pálpebra; B: Aspecto macroscópico da área da pálpebra inferior direita de coelho reparada com cartilagem auricular alógena, aos 30 dias de pósoperatório. Observa-se a pálpebra anatomicamente restaurada (seta).

Em todos os animais ocorreu o crescimento de pêlos no local onde foi realizado o procedimento cirúrgico. Pela avaliação microscópica, não se observou presença de cartilagem auricular nos animais submetidos ao enxerto palpebral, o que sugere sua absorção. Notou-se, ainda, nesses animais, moderada quantidade de tecido de granulação maduro e organizado. Já na avaliação nos do GC, encontrou-se moderada quantidade de tecido de granulação organizado e imaturo. Estes 
resultados assemelham-se aos observados por Marks et al. (1989), após o uso do enxerto de cartilagem auricular autógena, na pálpebra de homem, onde relataram que a cartilagem, quando enxertada, melhora a cicatrização tecidual.

\section{CONCLUSÃO}

A enxertia de cartilagem auricular alógena, conservada em solução saturada de $\mathrm{NaCl}$ no reparo de lesões induzidas na pálpebra inferior de coelhos, diminuiu a retração cutânea cicatricial, com boa integração tecidual, possibilitando melhora na estética palpebral.

\section{REFERÊNCIAS BIBLIOGRÁFICAS}

ABLA, L.E.F.; ISHIZUKA, M.M.A. Fisiopatologia das feridas. In: FERREIRA, L.M. Manual de cirurgia plástica. São Paulo: Atheneu, 1995. p.5-11.

BANKS, W.J. Tecido de sustentação: cartilagem. Histologia veterinária aplicada. 2.ed. São Paulo: Manole, 1992. cap. 8, p.124-136.

BRIGHTMAN, A.H.; HELPER, L.C. Full thickness resection of the eyelid. J. Am. Anim. Hosp. Assoc., v.14, p.483, 1978.

BRUN, M.V.; PIPPI, N.L.; DREIMEIER, D. et al. Solução hipersaturada de sal como conservante de pericárdio canino utilizado na reparação do músculo reto abdominal de ratos wistar. Cienc. Rural, v.32, p.1019-1025, 2002.

FREITAS, P.M.C. Reparo da parede torácica de coelhos com cartilagem auricular de cães preservada em glicerina a 98\% e com pedículo dos músculos serrátil ventral e grande dorsal. 2003. 32f. Tese (Mestrado) - Universidade Federal de Uberlândia, Uberlândia, MG.

FREITAS, P.M.C. Eletroacupuntura no reparo do tendão calcanear comum em coelhos após enxertia com peritônio bovino. 2006. 92f. Tese (Doutorado) Universidade Estadual Paulista, Jaboticabal, SP.

GABRIELLI, M.F.R.; VICENZO, P.; SNATIMERO, S.A. et al. Autogenous transplantation of rib cartilage, preserved in glycerol, to the malar process of rats: a histological study. J. Nilion. Univ. School Dent., v.28, p.87-99, 1986.

JACKSON, I.T.; DUBIN, B.; HARRIS J. Use of continued and stabilized conchal cartilage grafts for lower eyelid support: a preliminary report. Plast. Reconstr. Surg., v.83, p.636-640, 1989.

JONES, T.C.; HUNT, R.D.; KING, N.W. Inflamação e reparo. Patologia veterinária. 6. ed. São Paulo: Manole, 2000. p.119-133.

LEWIN, G. Eyelid reconstruction in seven dogs using a split eyelid flap. J. Small Anim. Pract., v.44, p.346$351,2003$.

MANDELBAUM, S.H.; SANTIS, E.P.; MANDELBAUM, M.H.S. Cicatrização: conceitos atuais e recursos auxiliares - Parte I. An. Bras. Dermatol., v.78, p.393-408, 2003.

MARKS, M.W.; ARGENTA, L.C.; FRIEDMAN, R.J. Conchal cartilage and composite grafts for correction of lower lid retraction. Plast. Reconstr. Surg., v.83, p.629-635, 1989.

MOORE, C.P. Afecções das pálpebras, conjuntiva e terceira pálpebra. In: BOJRAB, M.J. Mecanismos da moléstia na cirurgia dos pequenos animais. 2.ed. São Paulo: Manole, 1996. p.163-171.

PENA, T.M.; GARCIA, F.A. Reconstruction of the eyelids of a dog using grafts of oral mucosa. Vet. Rec., v.144, p.413-415, 1999.

SAMPAIO, R.L.; TANZANI, J.J.T.; RODRIGUES JÚNIOR, V. et al. Aspectos clínicos e imunopatológicos da ceratoplastia com membrana amniótica xenógena fresca e conservada em glicerina. Estudo experimental em coelhos. Arq. Bras. Med. Vet. Zootec., v.58, p. 1077-1085, 2006.

SCHMID, T.K.; BERTANI, C.; MARTANO, M. et al. Reconstruction of the lower eyelid by third eyelid lateral advancement and local transposition cutaneous flap after "en bloc" resection of squamous cell carcinoma in 5 cats. Vet. Surg., v.34, p.78-82, 2005.

SLATTER, D. Fundamentals of veterinary ophthalmology. 2.ed. Philadelphia: W.B. Sauders, 1990. p.35-61.

STEGMAN, S.J.; TROMOVITCH, T.A.; GLOGAU, R.G. Basics of dermatological surgery. Mosby, 1982. p.132-140. 